\title{
Hydraulic Expansional Tieback Cylinder and Difunctional Expansional Liner Hanger
}

\author{
Xiaojun $\mathrm{Li}^{1,2}$, Deguo $\mathrm{Wang}^{1}$, Feiyue Wang ${ }^{2}$, Jibin $\mathrm{Zhao}^{2}$, Junfeng Zhang ${ }^{2}$ \\ ${ }^{1}$ Institute for Machinery and Storage and Transport of Petroleum University in Beijing, Beijing \\ 102249, China \\ ${ }^{2}$ CNPC Xibu Drilling Engineering Company Limited, Karamay 834000, Xinjiang, China
}

Keywords: Expansional Liner Hanger; Completion Engineering; Packing Element; Packing Hanger

\begin{abstract}
There is a problem of poor cementing quality at the overlay segment of the liner hanger in the conventional liner hanger cementing and it can be solved by the technique of expandable liner hanger which adopts the steel tube expansion and the high strength rubber materials as the hermetic hanging mechanism; the new liner hanger in this thesis has integrated the advantages of the current conventional liner hanger and the expandable liner hanger and it provides reliability for upgrading the cementing for its compact as well as reasonable structure, easiness to use, low cost and the duplicato-bearing of the tieback cylinder and the slips thus the setting is more dependable. The well cementaion can be provided with more reliability.
\end{abstract}

\section{Introduction}

The technology of liner hanger cementing has been broadly used in large domestic as well as abroad oilfields on account of its low cost, low cavity drag of water injection cement sheath and convertible atress of tubular column. As a critical element of liner cementing, liner hanger has been growing into concern of insiders. Conventional liner hanger system is hung on upper annular tubes through slips and it is not provided with packing therefore it has a problem of poor cementing quality at the overlay segment of the liner hanger and it has become a weak link in the tubular columns of liner well completion.

With the increase of exceptional wells like deep wells, extradeep wells and horizontal wells, the well condition is getting more and more complicated. Under that hostile well condition, problems of conventional liner hangers would be exposed such as low reliability of setting and low bearing capacity, etc. and the construction progrss as well as the cementing quality would be seriously affected by frequent failures of the setting.

Therefore the expandable liner hanger system was developed in allusion to the defects of conventional liner hangers and this system was constituted of hanger with packer, tieback cylinder, running tool as well as the expansion tool. This system provided effective pack for liner hangers and casing pipe annulus and it was equiped with efficient duplicato-bearing thus the defect of conventional liner cementing could be solved and the success possibility as well as the cementing quality could be improved.

The new type liner hanger in this thesis had integrated the advantages of the current conventional liner hanger and the expandable liner hanger and it provided reliability for upgrading the cementing for its compact as well as reasonable structure, easiness to use, low cost and the duplicato-bearing of the tieback cylinder and the slips thus the setting was more dependable. 


\section{Components of Tools}

This new liner hanger was mainly composed of hanger assembly, running tools and the expansion tools. The structure diagram is as shown in Fig. 1.

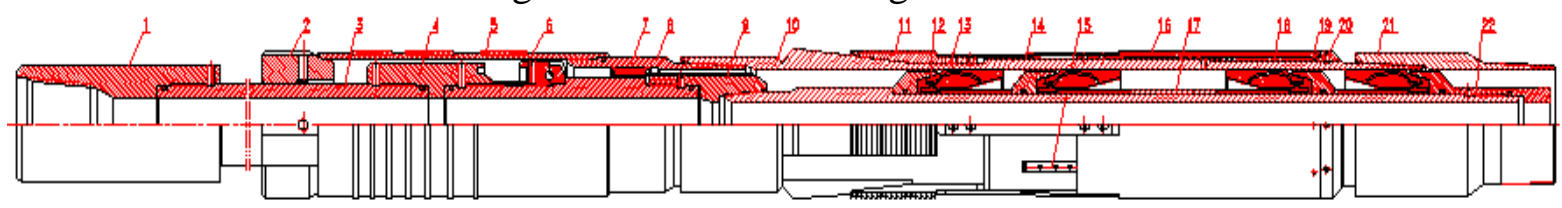

Fig.1. structure diagram of the new liner hanger

1) Hanger assembly

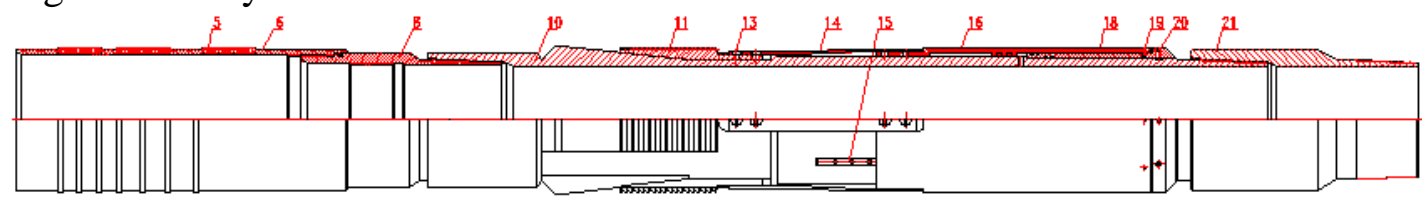

Fig.2. structure diagram of the hanger assembly

As it's shown in Fig.2, the hanger assembly was composed of seal packing element(5)、 tieback cylinder(6)、 unscrewing joint(8)、 hanger body(10)、slips(11)、 tacking(13)、 connecting rod(14)、 guide track rails(15)、 hydraulic cylinder(16)、 packing element A(18)、shear pins(19)、 tacking B(20)、 adapter substitutes (21)

2) The running tool

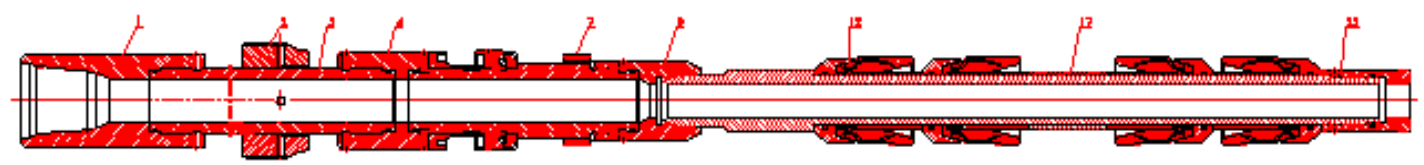

Fig.3. structure diagram of the running tool

As it's shown in fig.3: the running tool was composed of top joint(1)、 briquette(2)、adapter substitutes A(3)、adapter substitutes(4)、 unscrewing gears(7)、 adapter substitutes C(9)、 packing leather(12)、spacer sleeves(17)、joints(22)

3) The expansion tool

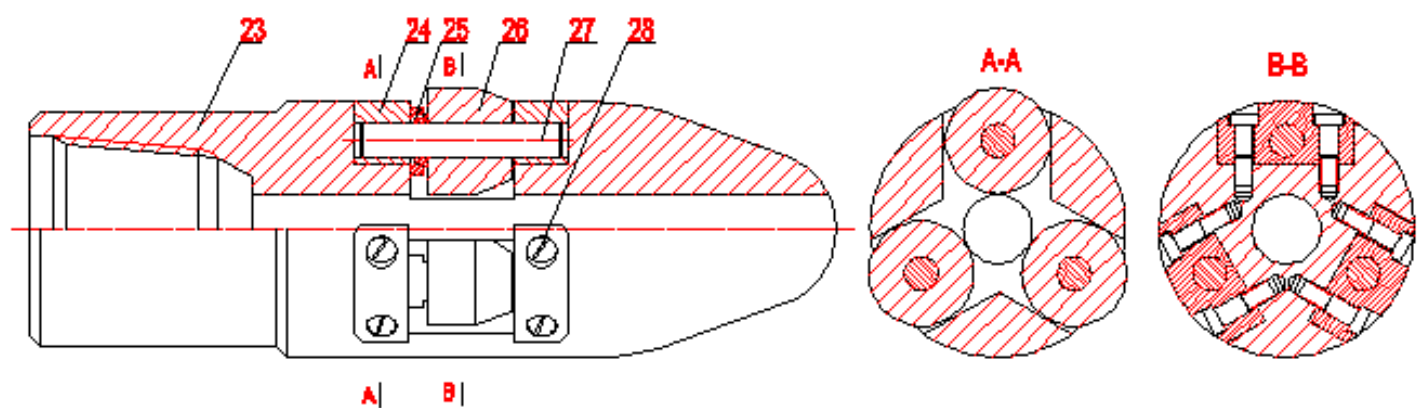

Fig.4. structure diagram of theexpansion tool

As it's shown in Fig.4: the expansion tool was composed of the body of expansion tool(23)、 fixed block(24)、 bearing(25)、idler wheels(26)、 stationary shaft(27)、 screws(28)

\section{Characteristics of the Tools}

1) There were three ring grooves on the tieback cylinder(6)of the hanger assmebly and the packing elements(5)was equiped in the ring grooves working as sealing.

2) the left-hand threads were equiped in the unscrewing joints as well as in the unscrewing gears of the running tool. The releasing of unscrewing was completed through the tying of those two

3) in the running tool, there were four packing leathers, paired and in the same direction. The 
outside diameter size combined with the hanger body was slightly bigger than the inside diameter of the hanger body, thus the sealing could be effective.

4) there were guide track rails on the hanger body to prevent the hydraulic cylinder from spining, thus to protect the hydraulic cylinder.

\section{The Operating Principles}

1) The operating principle of the expansion tool

The structural characteristic of the expansion tool was to install several sets of idler wheels on the circumferences along the expansion tool. Independently, idler wheels would move to the outside diameter simultaneously under the pressure of the high-pressure liquid to expand the expanding materials. When setting the expansion, the expansion tool would be moving rectilinearly at the axial direction and at the circumferential direction, it would be moving rotationally along with the drilling tool.

Under the hydraulic pressure, idler wheels would make efforts to proceed extrusion and expansion on the expansion body; under the thrust of the drilling tool as well as the rotation, the expansion body would expand symmetrically at the radial direction and the contact between idler wheels and the expansion body was line contact.

When the hydraulic pressure was extruding idler wheels to the outside diameter direction, there was certain flexible space during the radial motion. When the outside annular tubes were irregular, it was feasible to expand based on the inner shape of the outside annular tubes and the expanded expansion body would be more closely appressed to the inside of the outside annular tubes thus the packing of the hanger and the hanging force could be improved therefore the jam could be avoided.

The operating principle of this expansion method was carrying out spining, expansion and axial feed simultaneously thus there would be less axial force needed in the expansion operation.

This kind of expansion was flexible expansion. It was well-adapted to the inwall of the outside annular tubes and the expansion body could be expanded more longer; flexible expansion could reduce the jam risk during the expansion setting thus to improve the reliability of expansional liner hanger.

2) The operating principle of the new liner hanger

The setting was proceeded after the liner hanger reached its designated spot and the pressure was built in the tubes. When the pressure reached a certain value, the shear spin would be sheared, and the slips, connecting rod, hydraulic cylinder as well as the packing element A would move upward under pressure, then when the pressure reached a certain value, the slips would be operating between the outside annular tudes and the hanger boby, then to recoil down the drill stem. After assuring the setting was done, spined the drill stem and disengaged the unscrewing gears and the unscrewing joint, then to release the running tool after it was done, next to lift the running tool to the well mouth then to down pass the expansion tool. When the expansion tool encountered the tieback cylinder, it would be jammed. At this time, it should be uplifted a little and passed down in spining. It could be pressurized when in jam, then to uplift a little after passing down a certain distance. Repeatedly to pass down in spining with the same distance, then lifted the drill and the operation was completed.

\section{Conclusion and Understanding}

1) Conventional liner hanger system is hung on upper annular tudes through slips and it is not provided with packing therefore it has a problem of poor cementing quality at the overlay segment of the liner hanger and it has become a weak link in the tubular columns of liner well completion.

2) there is a problem of poor cementing quality at the overlay segment of the liner hanger in the conventional liner hanger cementing and it can be solved by the technique of expandable liner hanger which adopts the steel tube expansion and the high strength rubber materials as the hermetic hanging mechanism thus the well cementaion can be provided with more reliability.

3) The expansion in this thesis is spining idler wheel expansion and it is flexible and 
well-adapted to the inwall of the outside annular tubes. Flexible expansion can reduce the jam risk during the expansion setting thus to improve the reliability of expansional liner hanger.

4) The new liner hanger in this thesis has integrated the advantages of the current conventional liner hanger and the expandable liner hanger and it provides reliability for upgrading the cementing for its compact as well as reasonable structure, easiness to use, low cost and the duplicato-bearing of the tieback cylinder and the slips thus the setting is more dependable. After the expansion, when the packing element of the tieback cylinder is extruded between the hanger and the upper annular tubes, the liner hanger and the casing annular can be well-packed, thus the packing can be highly improved.

\section{References}

[1] Yu Jinling, Zhou Yanjun, Wang Xizhou. Primary Research on the Application of Expansional Tubes [J]. Oildrilling Operation, 2002,30(5):55 57.

[2] Guo Zhaohui, Ma Lanrong, Zhu Heming. The New Progress in Abroad Expansional Liner Hanger. [J]. Petroleum Machinery, 2008, 36(5):66 69.

[3] Tang Ming, Teng Zhaozheng, Ning Xuetao. Research and Application of Expansional Liner Hanger. [J]. Art of Oildrilling. 2009,31(6):115 118.

[4] Yao Huiqian, Ma Lanrong, Guo Zhaohui, Jiang Xiangdong. The Technology and the Application of Expansional Liner Hanger. [J]. Oilfield Equipment, 2010,38(1):73 76. 